\title{
Article
}

\section{Protein detection using hydrogel-based molecularly imprinted polymers integrated with dual polarisation interferometry}

Reddy, Subrayal M, Hawkins, DM, Phan, QT, Stevenson, D and Warriner, K

Available at http://clok.uclan.ac.uk/13673/

Reddy, Subrayal M ORCID: 0000-0002-7362-184X, Hawkins, DM, Phan, QT, Stevenson, D and Warriner, K (2012) Protein detection using hydrogel-based molecularly imprinted polymers integrated with dual polarisation

interferometry. Sensors and Actuators, B: Chemical, 176 (Januar). 190 - 197.

It is advisable to refer to the publisher's version if you intend to cite from the work. http://dx.doi.org/10.1016/j.snb.2012.10.007

For more information about UCLan's research in this area go to http://www.uclan.ac.uk/researchgroups/ and search for <name of research Group>.

For information about Research generally at UCLan please go to http://www.uclan.ac.uk/research/

All outputs in CLoK are protected by Intellectual Property Rights law, including Copyright law. Copyright, IPR and Moral Rights for the works on this site are retained by the individual authors and/or other copyright owners. Terms and conditions for use of this material are defined in the policies page. 


\section{Accepted Manuscript}

Title: Protein Detection using Hydrogel-based Molecularly Imprinted Polymers Integrated with Dual Polarization Interferometry

Author: Subrayal M. Reddy Daniel M. Hawkins Quan T. Phan Derek Stevenson Keith Warriner

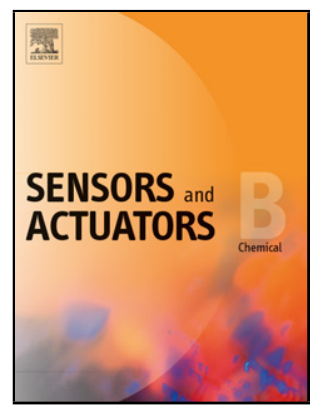

PII: S0925-4005(12)01031-3

DOI:

Reference: doi:10.1016/j.snb.2012.10.007

To appear in: $\quad$ Sensors and Actuators B

Received date: $\quad$ 27-7-2012

Revised date: 28-9-2012

Accepted date: $\quad$ 2-10-2012

Please cite this article as: S.M. Reddy, D.M. Hawkins, Q.T. Phan, D. Stevenson, K. Warriner, Protein Detection using Hydrogel-based Molecularly Imprinted Polymers Integrated with Dual Polarization Interferometry, Sensors and Actuators B: Chemical (2010), doi:10.1016/j.snb.2012.10.007

This is a PDF file of an unedited manuscript that has been accepted for publication. As a service to our customers we are providing this early version of the manuscript. The manuscript will undergo copyediting, typesetting, and review of the resulting proof before it is published in its final form. Please note that during the production process errors may be discovered which could affect the content, and all legal disclaimers that apply to the journal pertain. 

Polymers Integrated with Dual Polarization Interferometry.

10

11

12

13 Subrayal M. Reddy ${ }^{* 1}$, Daniel M. Hawkins ${ }^{1}$, Quan T Phan ${ }^{1}$, Derek Stevenson ${ }^{1}$ and Keith Warriner ${ }^{2}$

1. Department of Chemistry, Faculty of Engineering and Physical Sciences, University of Surrey, Guildford, Surrey, GU2 7XH, UK.

2. Department of Food Science, University of Guelph, Guelph, Ontario, N1G 2W1, Canada

21 Tel 01483686396

Fax 01483686401 


\section{Abstract}

25 A polyacrylamide-based molecularly imprinted polymer (MIP) was prepared for bovine haemoglobin (BHb). A $3 \mathrm{mg} / \mathrm{ml}$ solution of $\mathrm{BHb}$ was injected over a dual polarisation interferometer (DPI) sensor to form a physisorbed layer typically of $3.5 \pm 0.5 \mathrm{~nm}$ thickness. Onto the pre-adsorbed protein layer, 28 MIP and NIP (non-imprinted polymer) were separately injected to monitor the interaction of BHb MIP or NIP particles under different loading conditions with the pre-adsorbed protein layer. In the case of NIP flowing of the protein layer, there was negligible surface stripping of the pre-adsorbed protein. When a protein-eluted sample of MIP particles was flowed over a pre-adsorbed protein layer on the sensor chip, the sensor detected significant decreases in both layer thickness and mass, suggestive that protein was being selectively bound to MIP after being stripped-off from the sensor surface. We also integrated thin-film MIPS for BHb and BSA onto the DPI sensor surface and were able to show that whereas BHb bound selectively and strongly to the BHb MIP thin film (resulting in a sustained increase in thickness and mass), the $\mathrm{BHb}$ protein only demonstrated transient and reversible binding on the BSA MIP. MIPs were also tested after biofouling with plasma or serum at various dilutions. We found that serum at $1 / 100$ dilution allowed the MIP to still function selectively. This is the first demonstration of MIPs being integrated with DPI in the development of synthetic receptor-based optical protein sensors. 


\section{Introduction}

Molecularly imprinted polymers (MIPs) continue to receive much attention in research effort as they promise (and in some cases are delivering) synthetic materials capable of mimicking the selective binding function of antibodies and enzymes. The implications for such biomimicry are immense in the field of biosensor development and novel drug delivery modes. Over the past decade, there has been an exponential increase in research activity in developing hydrogel-based molecularly imprinted polymers (HydroMIPs) for the imprinting of proteins [1]. Hydrogels are insoluble, crosslinked polymer network structures composed of hydrophilic homo- or hetero-co-polymers, which have the ability to absorb significant amounts of water [2]. Monomers that have commonly been used for non-covalent molecular imprinted hydrogels are generally chosen on their ability to form weak hydrogen bonds between the monomer and the template [2-4]. Polyacrylamide hydrogels are known to be very inert, offer hydrogen bonding capabilities, and are biocompatible. For these reasons, acrylamide has been commonly used for molecular imprinting [5-9].

The use of optical sensor platforms in conjunction with imprinted polymers have been recently reported, primarily detailing the use of SPR [10] and quantum dots/array technologies [11-12]. Both applications have been reviewed in depth by Al-Kindy et al. [13].

Interferometric sensors based on dual polarisation interferometry (DPI) can be used for biological detection and the sensing is accomplished by directly monitoring a bioconjugate reaction occurring within an evanescent field extending out from the interferometer's sensing channel [14]. There are no subsequent steps, which are typical in many other sensing schemes, in which a second bioconjugate is reacted with the first to produce a sandwich complex.

The optical analytical technique has been designed specifically for the study of thin films, which uses electromagnetic evanescent wave probes to characterise the film above a planar waveguide surface. By including an optical bridge in the form of a buried reference waveguide, the sensitivity of thin film 
measurements is maximised with the resolutions determined by the interaction length between thin film and the evanescent field [15].

The measurement principle involves the use of a HeNe laser light $(\lambda=632.8 \mathrm{~nm})$ source coupled to the end facet of a silicon substrate and a ferroelectric liquid crystal halfwave plate switches the plane of polarisation of the input beam between Transverse Electric (TE) and Transverse Magnetic (TM) at frequencies of typically $50 \mathrm{~Hz}$. At the output, interference fringes in the far-field form on a digital camera screen, with the fringes being representative of the relative phase position of the sensing and reference light paths at the output. Any thin film changes thereof on the sensor surface of the waveguide will interact with its evanescent field and change its effective refractive index (RI). Such changes will move the phase of the light exiting the sensing waveguide, and the position of the fringes on the camera will move.

The phase positions refer to the two orthogonal polarisations (TE and TM) that are measured by the instrument. The absolute effective index of a waveguide mode is found by solving Maxwell's equations of electromagnetism for a system of uniform multiple dielectric layers in which the fields in the semi-infinite bounding layers are exponentially decaying solutions. The parameters required are the RI and thickness of each layer for each of two polarisations. Provided the input information is complete, an effective index value is obtained which is representative of the distribution of optical power amongst the layers. If a new layer is introduced to (or removed from) the system, it will alter the effective index. For each of the two polarisations, the new effective index can satisfy a continuous range of thickness and refractive index values. However, there will only be one unique combination that satisfies the index of the two polarisations.

Using different evanescent field profiles, various characteristics of the thin-film can be resolved. Different polarisations are used to resolve the optical density and the thin film thickness simultaneously at resolutions of $<1 \mathrm{pg} / \mathrm{mm}^{2}$ and $<10 \mathrm{pm}$ [16]. If a new layer is introduced to (or 
removed from) the system, it will alter the effective index. For each of the two polarisations, the new effective index can satisfy a continuous range of thickness and refractive index values. However, there will only be one unique combination that satisfies the index of the two polarisations.

97 The technique allows the precise behaviour of layers to be determined in terms of both their density

98 (absolute RI) and thickness in real time and therefore, mass, surface coverage and concentration can

99 be calculated. Integral to this is the calibration of both the sensor chip and bulk refractive index, which allows the accurate derivation of the data, and takes into account subtle changes film parameters and variations in chip structure which may give rise to errors in sensitivity. As a result, the DPI technology presents the opportunity to further provide a rapid method for the characterisation and quantification of molecular binding events.

To date, work using dual polarisation interferometry has been focused on investigations into the studying nucleic acid interactions [17], DNA immobilisation [18], antibody-antigen interactions [19], protein characterisation [20-23], and polymer characterisation [24-26]. Herein is the first report of DPI to characterise HydroMIPs and develop thin film HydroMIP-based protein sensors. 
Acrylamide, glacial acetic acid $(\mathrm{AcOH})$, ammonium persulphate (APS), N, $\quad \mathrm{N}^{\prime} \quad$ -

111 methylenebisacrylamide; ethanol (EtOH), sodium dodecyl sulphate (SDS); N, N, N', N 112 tetramethylethyldiamine (TEMED), phosphate buffered saline (PBS), succinic acid, tris base, and tris

113 hydrochloric acid were purchased from Sigma-Aldrich. Bovine haemoglobin (BHb); and bovine serum

114 albumin (BSA) were purchased from Sigma-Aldrich. Unmodified silicon oxynitride sensor chips were

115 purchased from Farfield Sensors (Crewe, UK) and a programmable syringe pump (PHD 2000) was

116 purchased from Harvard Apparatus (Holliston, MA, USA). Plastic syringes ( $1 \mathrm{ml} \& 5 \mathrm{ml}$ with Leur Lock

117 fittings) were purchased from Becton Dickinson UK Ltd (Oxford, UK). Pooled plasma and serum samples were used in the biocompatibility studies.

\subsection{Preparation of Solutions}

A solution of $10 \%(\mathrm{w} / \mathrm{v}) \mathrm{AcOH}: \mathrm{SDS}$ was prepared for use in the wash stages before and after the reloading stage of the rebinding studies. SDS $(10 \mathrm{~g})$ was dissolved in $90 \mathrm{ml}$ of MilliQ water. $10 \mathrm{ml}$ of $\mathrm{AcOH}$ was added and mixed thoroughly using a magnetic stirrer. $\mathrm{A} 0.3 \mathrm{mg} / \mathrm{ml}$ stock solution of $\mathrm{BHb}$ in RO water was prepared, as were SDS solutions to give final percentages of $10 \%, 5 \%, 2 \%, 0.5 \%, 0.1 \%$ and $0.05 \%(\mathrm{w} / \mathrm{v})$. A reverse osmosis (RO) water stock solution was degassed under vacuum (with stirring) for $10 \mathrm{mins}$, as was an $80 \%(\mathrm{w} / \mathrm{w})$ solution of ethanol $(\mathrm{EtOH})$ in degassed RO water. A stock solution of bovine haemoglobin (BHb) template solution was prepared in MilliQ water.

\subsection{HydroMIP production}

Molecularly imprinted (MI) hydrogels were produced using our optimised methodology [5]. It was shown that when imprinting $\mathrm{BHb}$ using bulk polyacrylamide hydrogels, a $10 \%$ crosslinked polyacrylamide/ $\mathrm{N}, \mathrm{N}^{\prime}$ - methylenebisacrylamide hydrogel produced the optimal imprint for $\mathrm{BHb}$ in 
134 (NIP). Hawkins et al. also demonstrated that using a 10\% AcOH:SDS during the elution stage of the rebinding studies performed resulted in optimal protein recovery for BHb specific MIPs.

Therefore, MI hydrogels were produced as follows for $1 \mathrm{ml}$ of gel: $54 \mathrm{mg}$ of functional monomer

137 (acrylamide), $6 \mathrm{mg}$ of crosslinker ( $\mathrm{N}, \mathrm{N}^{\prime}$ - methylenebisacrylamide), and $12 \mathrm{mg}$ of template protein were all dissolved in PBS or MilliQ water and added together to create the MIP solution. $20 \mu \mathrm{l} / \mathrm{ml}$ of a $10 \%(\mathrm{w} / \mathrm{v})$ ammonium persulfate (APS) solution was added to the MIP solution, and the solution was purged with nitrogen for 5 minutes. Once the solution was degassed, $20 \mu \mathrm{l} / \mathrm{ml}$ of a $5 \%(\mathrm{v} / \mathrm{v}) \mathrm{N}, \mathrm{N}, \mathrm{N}^{\prime}$, $\mathrm{N}^{\prime}$ - tetramethylethyldiamine (TEMED) was added and the solution was then left to polymerise overnight at room temperature. We looked at freshly prepared MIP following granulation and water washing (hereafter, referred to as MIP1). A sample of MIP1 was washed with SDS and acetic acid followed by a further water wash to produce sample MIP2. MIP3 was the sample produced after MIP2 was reloaded with target protein (bovine haemoglobin).

For every BHb MIP created a NIP was also created using the same material concentration as the MIP but without the protein template in order to serve as a control. BSA MIPs were also prepared using $12 \mathrm{mg}$ of BSA template instead of BHb. The BSA MIPs were used as control polymers for BHb binding to be compared against BHb MIPs.

\subsection{Dual Polarisation Interferometry AnaLight ${ }^{\circledR}$ Bio200 Set-up}

All DPI experiments were performed on the Farfield AnaLight ${ }^{\circledR}$ Bio200 instrument, which had been installed and internally calibrated by the manufacturer. The AnaLight ${ }^{\circledR}$ Bio200 instrument provides a flexible platform that incorporates a modular fluidics arrangement to enable a wide range of experimentation to be undertaken. Integral to all experimentation is the sensor chip used to exploit the technology. The sensor is a multiplayer deposited waveguide structure on a silicon wafer, and is manufactured to a high tolerance to enable accurate measurement to take place. Opening windows 
in the top cladding of the waveguide define the two active areas on the chip, which also define the active path length of the sensor and are lithographically produced to micron levels of precision. The precise sensitivity is dependant on the waveguide thickness and refractive index. Many variations in chip functionalisation and design are available and should be used following the careful consideration of the method of immobilisation of molecules on the sensor surface. Hydroxylation of the silicon oxynitride sensor is one of the simplest and most commonly employed surface modifications and is typically used for the physisorption of proteins and the functionalisation of "smart" polymers. Modifications in chip functionalisation can also include amination, biotinylation and thiolation to name but a few.

The fluidic design of the AnaLight ${ }^{\circledR}$ Bio200 is based on a flow cell, which comprises two sample chambers fitted with two independent feeds and drains, and makes up the core of the system. The two channels can be configured in series or (more commonly) in parallel with a number of sample introduction methods possible that should be chosen to optimise the experimental aim. When performing an experiment, a pump supplies running buffer to the sensor chamber, with an injection loop allowing the controlled introduction of the sample. The AnaLight ${ }^{\circledR}$ Bio200 instrument software also allows the extensive post experimental analysis of results using an analysis of the interference fringe position and operation of Maxwell's equation. The technique allows the precise behaviour of layers to be determined in terms of both their density (absolute RI) and thickness in real time and therefore, mass, surface coverage and concentration can be calculated.

Each experiment was carried out on an unmodified silicon oxynitride sensor chip and analysed using the AnaLight $^{\circledR}$ Bio200 software (version 2.1.12/inject application version 1.0.1). Prior to each experiment, RO water running buffer and $80 \%(w / w) ~ E t O H$ was degassed. A $50 \mathrm{ml}$ syringe was filled with the degassed running buffer, and fitted into the syringe pump. The Farfield fluidic system was attached to the buffer syringe, the flow rate set at $200 \mu \mathrm{l} / \mathrm{min}$, and flow started (initially directed to 
waste) to eliminate any air bubbles from the fluidic piping immediately associated to the buffer reservoir. The flow rate was changed to $100 \mu \mathrm{l} / \mathrm{min}(50 \mu \mathrm{l} / \mathrm{min}$ per channel) to set the experimental fringes. Degassed EtOH was loaded and injected across both channels in duplicate to wash the new sensor chip before switching back to buffer and waiting for the fringes to stabilise (approximately 45seconds). The automated fringe selection function was employed to select the fringe positions, with good amplitude and agreement being the key factors governing fringe choice. Prior to each experiment, the sensor chip was calibrated by performing a routine EtOH injection. The injection loop was filled with EtOH and injected across the experimental channels being used at $100 \mu \mathrm{l} / \mathrm{min}$ initially (3mins) before being changed to $15 \mu \mathrm{l} / \mathrm{min}$ per channel $(30 \mu \mathrm{l} / \mathrm{min}$ if both channels were used). The injection was allowed to run completely through to running buffer (rather than abruptly stopping the injection) over a period of approximately $20 \mathrm{mins}$.

\subsection{DPI - BHb Physisorption Studies}

The DPI system was set up and calibrated as described above. A $0.3 \mathrm{mg} / \mathrm{ml}$ BHb solution was loaded into the injection loop, and injected across both experimental channels at a flow rate of $50 \mu \mathrm{l} / \mathrm{min}$ for approximately six minutes. The flow was switched back to the buffer, and the sensor chip recycled by injecting EtOH in duplicate followed by $2 \%$ SDS at $100 \mu \mathrm{l} / \mathrm{min}$. The DPI instrument phase responses were recorded throughout the experiment.

Non-imprinted HydroNIP control gels were diluted $1 / 10$ and $1 / 15$ using RO water. The 1:15 dilution of the HydroNIP suspension was loaded into the injection loop and injected across the sensor surface at $50 \mu \mathrm{l} / \mathrm{min}$ for approximately six minutes, followed by an EtOH injection each time at then repeated with MIP1, MIP2 and MIP3. were injected in an identical fashion, followed once again by EtOH. Upon conclusion of the experiment, the sensor chip was recycled by injecting $2 \%$ SDS at $100 \mu \mathrm{l} / \mathrm{min}$. The experiment was 
A $0.3 \mathrm{mg} / \mathrm{ml} \mathrm{BHb}$ solution was loaded and injected as before. Approximately five minutes after the end of the $\mathrm{BHb}$ injection, a 1:15 dilution of the HydroNIP control was injected in duplicate as previously described. Two EtOH injections and a 2\% SDS injection were then performed at $100 \mu \mathrm{l} / \mathrm{min}$ to recycle the sensor chip. This cycle $(\mathrm{BHb}$; hydrogel sample $\times 2$; EtOH $\times 2$ and $2 \%$ SDS) was repeated in an identical fashion for the remaining gel samples (MIP 1, MIP 2 \& MIP 3).

\subsection{DPI - Data Analysis}

All experimental analyses were performed in the first instance using the AnaLight ${ }^{\circledR}$ Bio200 software. In each experiment (where applicable), layer tables were constructed which in turn allowed the quantification of specific binding and analysis events in terms of changes in thickness, refractive index, layer density and mass of the deposited layers upon the sensor surface. All data were exported into Microsoft Excel, which was employed to produce graphical representations of the raw data obtained.

\subsection{Thin film MIP application to DPI chip}

Thin films were created by applying pressure to the hydrogel solutions over the optical waveguide chips. This was done by injecting $50 \mu$ l of free-radical initiated polymerising hydrogel solution over the channels of the DPI chip and placing an $18 \mathrm{~mm}^{2}$ cover slip over the chip, thereby sandwiching the hydrogel polymerising solution in between the cover slip and the DPI chip surface. Pressure $(2 \mathrm{kPa})$ was then applied using bronze weights placed on top DPI chip for 10 minutes. After polymerisation was completed, the weight and cover slip were removed the DPI chip was stored in a fridge at $4^{\circ} \mathrm{C}$ overnight. Dual polarisation interferometry was used to characterise the real time binding effects of $\mathrm{BHb}$ template molecules to $\mathrm{BHb}$ specific $\mathrm{MI}$ hydrogels. The selectivity and rebinding effect were characterised using BHb specific MIPs as MIPs selective for the reloaded template, and BSA specific 
MIPS as controls. DPI chips were first calibrated using blank chips. The materials used to calibrate

237

238

239

240

241

244 the chips were $80 \%$ ethanol and MilliQ water. The DPI chips were first exposed to running PBS buffer for $20 \mathrm{~min}$ at a flow rate of $50 \mu \mathrm{l} / \mathrm{min} .100 \mu \mathrm{g} / \mathrm{ml}$ of BHb template was then injected over both sets of MIPs for 10 minutes at $20 \mu \mathrm{l} / \mathrm{min}$ flow rate. This was followed by an injection of $100 \mu \mathrm{g} / \mathrm{ml}$ of BSA which was left to flow over the MIPs using the same association time and flow rate.

Stopping the flow of running buffer after $\mathrm{BHb}$ and $\mathrm{BSA}$ injections was also investigated to increase the association time of the proteins to the MIPs, however this did not have a major effect on the rebinding of $\mathrm{BHb}$ or BSA to the MIPs as results obtained were similar to those under constant flow conditions.

\section{Results \& Discussion}

\subsection{DPI Sensing of BHb Protein Adsorption}

Figure 1 shows the changes in thickness, mass and density observed due to BHb protein $(0.3 \mathrm{mg} / \mathrm{ml})$ adsorption on a cleaned DPI chip surface. As expected, both the thickness and mass of the deposited protein layer increase rapidly at first as protein physisorbs to the sensor surface. Upon switching the flow from $\mathrm{BHb}$ solution back to the running buffer, excess $\mathrm{BHb}$ is clearly removed from the sensor surface. It is probable that this was caused by the formation of a bi-layer of protein as a result of the relatively high concentration of protein deposited upon the sensor surface [21].

\section{$<$ INSERT FIGURE 1>}

It can be seen that the density of the deposited layer reaches a plateau with the continual accumulation of protein upon the surface. As the injection ends and the flow switches to buffer, the density of the deposited layer dramatically increases, at the same time as protein is removed from the surface (as indicated by the changes in thickness and mass). 
When the $\mathrm{BHb}$ molecules are removed, the remaining protein can re-organise and associate more strongly with the sensor surface allowing physisorption to occur to a greater degree [20]. The increase in the spatial association that occurs between the protein molecules and the sensor surface, could be resulting in a more densely bound protein layer due to the ability of the protein molecule to form hydrogen bonds with the sensor surface.

\subsection{DPI sensing of selective stripping of pre-adsorbed protein layers by MIP.}

All gels were granulated to $75 \mu \mathrm{m}$ (the internal diameter of the tubing in which fluid flow passes in the instrument, was $250 \mu \mathrm{m}$ ). Because of the viscous nature of the hydrogels, dilution was required in order for the gel particles to be dispersed enough to flow. Initial experiments showed that flow would not be possible at dilutions of $1: 2$ through to $1: 8$ as the samples were congealed resulting in potentially clogging the fluid channels. Dilutions of $1: 10$ and $1: 15$ were appropriate for the injection of HydroMIP and HydroNIP samples across the sensor surface. The MIP samples were found to be stable for at least over a 3 month period when stored at $4{ }^{\circ} \mathrm{C}$ when not in use. Table 1 summarises the change in thickness, mass and density for various injections of protein (BHb adsorption), followed by double injections of NIP, MIP1, MIP2 or MIP3.

$<$ INSERT TABLE 1>

\subsubsection{Effect of NIP on pre-adsorbed protein layer}

Table 1 shows the changes in thickness, mass and density of the deposited protein layer upon the sensor surface during protein deposition and following the injection of HydroNIP control gels. A final $\mathrm{BHb}$ layer with a thickness of $2.74 \mathrm{~nm}$ and a mass of $1.99 \mathrm{ng} / \mathrm{mm}^{2}$ was adsorbed upon the sensor surface following protein deposition. Following the injection of the first HydroNIP sample, there is a small decrease in both thickness and mass of layer, which rises slightly following the second HydroNIP injection. Overall, there is no significant protein stripping effect. This is expected, as other than the random formation of cavities that demonstrate the appropriate architecture and selectivity 
to accept the protein molecules, there is no reason why the control gel would strip protein from the sensor surface.

\subsubsection{Effect of MIP1 on pre-adsorbed protein layer}

285

286

287

The injection of $\mathrm{BHb}$ across the sensor surface results in a layer $4.32 \mathrm{~nm}$ thick with a mass of $2.39 \mathrm{ng} / \mathrm{mm}^{2}$ being deposited upon the sensor surface (see Table 1 ). The initial MIP 1 sample injection contributes a small increase in both mass and thickness, with the second injection contributing to a small decrease. The density of the protein layer fluctuates slightly, but overall, the MIP 1 sample has little effect, as would be expected, in the removal of BHb from the sensor surface. The imprinted cavities within the MIP 1 sample are still occupied with the original template protein, with very few (if any) imprinted cavities exposed. As a result, association between the immobilised protein and imprinted cavities could not occur explaining why the MIP 1 gels had no effect upon removal of protein from the sensor surface.

\subsubsection{Effect of MIP2 on pre-adsorbed protein layer}

Figure 2 shows the changes in thickness, mass and density of the deposited protein layer upon the sensor surface during protein deposition, followed by the injection of MIP 2 HydroMIP samples. Following the physisorption of $\mathrm{BHb}$ upon the sensor surface, a protein layer that was $4.43 \mathrm{~nm}$ thick with a mass of $2.48 \mathrm{ng} / \mathrm{mm}^{2}$ remained. Following the first MIP 2 injection, this layer decreased significantly in thickness to $3.38 \mathrm{~nm}$, and once again to $3.26 \mathrm{~nm}$ following the second injection. The mass responded in an identical manner with a decrease to $2.31 \mathrm{ng} / \mathrm{mm}^{2}$ and $2.26 \mathrm{ng} / \mathrm{mm}^{2}$

$<$ INSERT FIGURE 2>

respectively following the two MIP injections. The small change following the second injection in Fig 2 confirms that the majority of the stripping effect occurs as a result of the first injection. In contrast to the NIP control and MIP 1 samples, the MIP 2 sample which possessed exposed imprinted cavities, was able to strip away BHb from the sensor surface. The layer density values also support 
this event, as an increase from $0.55 \mathrm{~g} / \mathrm{cm}^{3}$ (BHb protein layer) to $0.68 \mathrm{~g} / \mathrm{cm}^{3}$ (injection 1 ) and $0.70 \mathrm{~g} / \mathrm{cm}^{3}$ (injection 2) was observed as protein was removed from the surface apparently allowing the remaining protein molecules to associate themselves in a denser fashion upon the sensor surface.

As previously observed, the deposition of $\mathrm{BHb}$ (in terms of thickness and mass) results in an immediate and distinctive (peaked) binding curve, followed by a plateau that relates to the remaining deposited protein layer.

Immediately following the first injection of HydroMIP, there is a rapid increase in the density of the protein layer. This suggests that protein is being removed from the sensor surface, which allows the remaining protein that has not been stripped to orientate itself upon the surface in a highly ordered manner (in comparison to the relative disorder of the saturated protein layer). Upon returning to running buffer, the density falls slightly but once again increases when the second HydroMIP injection is performed. An identical effect occurs, resulting in a final baseline density value that is higher than that obtained following the first injection and considerably higher than the value obtained prior to both the MIP2 injections.

The suggestion that protein is removed from the sensor surface is supported by the values relating to the decreased mass of the protein layer. Following the injection of both HydroMIP samples, the mass upon the sensor surface rises sharply, before decreasing to give values lower than those observed prior to the injections. This strongly suggests that protein is indeed being removed from the sensor surface by MIP2.

\subsubsection{Effect of MIP3 on pre-adsorbed protein layer}

In contrast to both NIP and MIP 1, the injection of the MIP 3 sample across the sensor surface results in an increase in thickness and mass and a decrease in density of the protein layer (Table 1), 
however not to the same degree as the MIP 2 sample comprising exposed (unoccupied) molecularly imprinted cavities.

The elevation in the density of the protein layer as a result of the injection of the MIP3 sample indicates that protein is being stripped from the sensor surface by the gel samples. It appears that the MIP 3 HydroMIP is behaving in a similar manner to that of MIP 2, but to a much lesser degree.

The MIP 3 sample is similar in nature to MIP 2 sample, but has been subjected to the rebinding of the target template molecule within the imprinted cavities that it possesses. The rebinding of the template molecule within these imprinted sites can be highly efficient $[5,27]$, however it cannot be assumed that it is a process that is $100 \%$ efficient and that every cavity becomes reoccupied following rebinding. Some imprinted cavities that have not been reoccupied by the template protein are available within the MIP3 sample. When the gel is removed by the buffer solution some surfaceadsorbed protein is stripped away with the gel. The above promising results demonstrate that we can distinguish between different MIP loading states using DPI sensing by monitoring their effect on a pre-adsorbed protein layer.

\subsection{Thin film HydroMIPs integrated to the DPI sensor and optimisation of biological conditions}

Having demonstrated the selective stripping-off of protein from the sensor surface by MIP2, we investigated the development of a thin-film MIP integrated to the DPI sensor. With the MIP attached to the sensor, we would effectively have the makings of biosensor for protein detection. Thin MIP films were prepared as detailed in Section 2.7. Instead of using a NIP control, we used a MIP prepared for BSA, a protein of similar molecular weight to haemoglobin. Thin-film MIPs for haemoglobin and BSA were prepared separately (as shown in the methods) and tested for their selectivity in rebinding haemoglobin. The sensing region of the DPI instrument used in this thesis typically extends to $500 \mathrm{~nm}$ from the waveguide surface of the DPI chips, therefore it was favourable to produce films less or equal in thickness to this parameter. The maximum thickness obtained for 

$\mathrm{kPa}$ pressure applied during film formation respectively. Gels prepared at $2 \mathrm{kPa}$ pressure demonstrated the highest degree of sensitivity in terms of changes in the mass and density of the polymers on the surface of the chip and were therefore investigated further for their selective nature. Prior to rebinding of $\mathrm{BHb}$ to either BHb MIP or BSA MIP, the MIP layer was washed with SDS to remove surface imprinted protein, followed by DI water to remove any residual SDS. Both the $\mathrm{BHb}$ and BSA MIPs were then exposed to $\mathrm{BHb}$. Selective binding of cognate protein for the BHb MIP gave a sustained increase in film thickness and mass (Fig 3), whereas when $\mathrm{BHb}$ was injected over the BSA MIP although there was an initial increase in film thickness and mass, the response was transient and returned to thickness and mass values before protein injection. This indicates that the there is no net non-specific binding of BHb to the BSA MIP (Fig 3).

The trace for $\mathrm{BHb}$ loading onto $\mathrm{BHb}$ MIP can be interpreted as a swelling after $\mathrm{BHb}$ is injected over the BHb MIP. The gel then relaxes, and interestingly, the mass of the layer increases. This increase in mass implies the reloaded $\mathrm{BHb}$ is adhering to the polymer as it flows over the $\mathrm{BHb}$ MIP. The thickness of the material remains at steady state, and the density of the material increases. This could indicate that the majority of the $\mathrm{BHb}$ rebinding is occurring in cavities below the surface of the film. The BHb MIP sensor exhibited a linear response up to $200 \mu \mathrm{g} / \mathrm{ml}$ with a limit of detection of $2 \mu \mathrm{g} / \mathrm{ml} . \mathrm{Hb}$ in urine in known as hemoglobinuria and can occur due to for example kidney cancer, burns, and malaria. Brian et al. [28] when using surface plasmon resonance detection of hemoglobin reported a very similar lower limit of detection of $1.3 \mu \mathrm{g} / \mathrm{ml}$. The mechanism of detection did not rely on a MIP layer but relied on rebinding of heme to surface immobilised apo-hemoglobin. Our lower limit of protein detection suggests that with some improvement in, for example, film thickness and MIP cavity density, the technique will be appropriate for the measurement of disease markers 
such as the prostate cancer markers, prostate specific antigen $(2-10 \mathrm{ng} / \mathrm{mL})$ in blood and engrailed-2 protein (>42.5 ng/mL) in urine [29] and other such biomarkers in blood.

In order to assess their suitability in real biological samples, HydroMIPs were investigated for their potential application for biological diagnostics using plasma and serum matrices as potential interferents for template protein rebinding. We applied thin films of a BSA MIP and investigated the effects of neat, $1 / 10$ and $1 / 100$ diluted plasma exposure of MIPs prior to template protein (BSA) rebinding (Table 2).

\section{$<$ Insert Table 2>}

As neat plasma is injected over a BSA MIP a very large thickness, mass, and density change occurs which exceeds the limitations of the DPI instrument. This could be due to swelling of the gel and the detection of highly concentrated plasma flowing over the channels by the DPI instrument. This event is followed by a decrease in mass and thickness, and an increase in density. The loss in mass and thickness of the layer is indicative of the majority of the reloaded plasma passing over the MIP, and that the MIP is exhibiting limited non-specific binding of the plasma proteins. Upon BSA reloading, a small contraction event occurs followed by re-swelling of the gel. A steady state response is then subsequently observed. The loss in mass and thickness observed after BSA reloading was 0.07 $\mathrm{ng} / \mathrm{mm}^{2}$ and $0.15 \mathrm{~nm}$ respectively, and an increase of density of $0.02 \mathrm{~g} / \mathrm{cm}^{3}$. This response indicates no specific rebinding of BSA to the BSA MIP which is likely due to protein fouling of the MIP from the plasma injected. This suggests that whole plasma as a sample matrix is not suitable for MIP use. When using a lowered concentration of plasma (1:10 dilution) the initial mass, thickness and density changes of the gel are significantly lower when comparing with whole plasma reloading. As the response of the layer reaches steady state, the mass and thickness of the gel demonstrate a lower steady state response compared with whole plasma, giving a difference of $0.22 \mathrm{ng} / \mathrm{mm}^{2}$ and $0.33 \mathrm{~nm}$ respectively. As BSA is reloaded onto the BSA MIP, a small contraction event occurs. This is followed by re-swelling of the gel and a steady state response. The response of the resolved mass, thickness 
and density of the gel did not change significantly after BSA reloading, which could indicate that even lowering the concentration of the plasma interferent by 1:10 dilution, a high degree of protein fouling still occurs in the gel. Lowering the concentration of plasma further to a 1:100 dilution, demonstrates an interesting effect for the BSA MIPs. As 1:100 diluted plasma is injected over the BSA MIP, the thickness, mass and density of the gel initially increase. This is followed by a gradual decrease in these parameters, which suggests that the injected plasma is flowing over the MIP and showing a low degree of non-specific rebinding. As BSA is subsequently injected over the BSA MIP, there is an initial decrease in mass and thickness of the gel, followed by an increase in these parameters. This suggests that BSA is stripping away non-specifically bound plasma from the MIP and replacing it with BSA. However, there is also a gradual decrease in thickness and mass after this event occurs, which could imply that the rebound BSA is also gradually being lost from the surface of the MIP. This was not ideal and so we investigated the use of serum at various dilutions to see the effect on MIP binding (Table 2). Again, neat and 1/10 diluted serum samples demonstrate a high degree of non-specific binding of proteins. Subsequent addition of template BSA leads to a decrease in thickness but no apparent change in mass, suggesting possibly that BSA is adsorbing to the MIP after some of the non-specifically bound serum proteins are removed. At 1:100 diluted serum, the serum proteins have a small to negligible effect on thickness and mass. Subsequent BSA addition results in selective uptake of these template molecules as evidenced by significant increases in thickness and mass. Our results suggest that further optimisation of MIPs applied to blood sample should be conducted using 1:100 diluted serum samples as this dilution demonstrates negligible fouling of MIP.

\section{Conclusions}

We have shown that when a layer of protein was physically immobilised upon the sensor surface, the cavity-containing HydroMIP gels clearly stripped protein from the sensor surface in contrast to non-imprinted polymer and the HydroMIP samples that did not possess available imprinted sites 
capable of accepting the template protein. This effect has been quantified in terms of layer thickness, mass and density, and this is a firm indication of the presence of imprinted cavities within the HydroMIP structure.

Thin film MIPs can be applied to the DPI sensor also. This section of work indicates that the HydroMIP materials, may play a significant role as the selective recognition material of a thin film MIP biosensor strategy. Possible applications of HydroMIPs generally extend to either diagnostics, such as detection of drugs, viruses, pesticides, toxins, or bacteria, or therapeutics i.e. controlled release systems. The HydroMIPs are able to retain their selectivity after exposure to real biological samples only when used in 1:100 diluted serum.

Acknowledgements.

We thank the EPSRC (EP/G104299/1) for supporting the work conducted. We also thank Dr Marcus Swann from the Farfield Group for his invaluable insights into DPI data interpretation.

[1] K. Haupt, Imprinted polymers - Tailor-made mimics of antibodies and receptors, Chemical

444 Communications 34 (2003) 171-178.

445 [2] M.E. Byrne, K. Park, N.A. Peppas, Microfabrication of intelligent biomimetic networks for 446 recognition of D-glucose, Advanced Drug Delivery Reviews 54 (2006) 149-161.

447 [3] X. Liu, J.S. Dordick, Sugar acrylate-based polymers as chiral molecularly imprintable hydrogels, Journal of Polymer Science Part A: Polymer Chemistry 37 (1999) 1665-1671.

449 [4] J.M. González-Sáiz, M.A. Fernádez-Torroba, C. Pizarro, Application of weakly basic copolymer polyacrylamide (acrylamide-co-N,N,'-dimethylaminoethyl methacrylate) gels in the recovery of citric acid, European Polymer Journal 33 (1997) 475-485. 
[5] D.M. Hawkins, D. Stevenson, S.M. Reddy, Investigation of protein imprinting in hydrogel-based molecularly imprinted polymers (HydroMIPs), Analytica Chimica Acta 542 (2005) 61-65.

454

455

456

457

458

459

460

461

462

463

464

465

466

467

468

469

470

471

472

473

474

475

476

477

478

479

[6] Y. Xia, T. Guo, M. Song, B. Zhang, B. Zhang, Hemoglobin recognition by imprinting in semiinterpenetrating polymer network hydrogel based on polyacrylamide and chitosan, Biomacromolecules 6 (2005) 2601-2606

[7] J.L. Liao, Y. Wang, S. Hjerten, Novel support with artificially created recognition for the selective removal of proteins and for affinity chromatography, Chromatographia 42 (1996) 259-262.

[8] S.H. Ou, M.C. Wu, T.C. Chou, C.C. Liu, Polyacrylamide gels with electrostatic functional groups for the molecular imprinting of lysozyme, Analytica Chimica Acta 504 (2004) 163-166.

[9] E. Saridakis, S. Khurshid, L. Govada Q. Phan, D. Hawkins, G.V. Crichlow, E. Lolis, S.M. Reddy N.E. Chayen, Protein crystallization facilitated by molecularly imprinted polymers, P. Natl. Acad. Sci. USA 108 (2011) 18566-18566

[10] J.M. Costa-Fernandez, R. Pereiro, A. Sanz-Medel, The use of luminescent quantum dots for optical sensing, Trends in Analytical Chemistry, 25 (2006) 207-218.

[11] C.I. Lin, A.K. Joseph, C.K. Chang, Y.D. Lee, Molecularly imprinted polymeric film on semiconductor nanoparticles - Analyte detection by quantum dot photoluminescence, Journal of Chromatography A 1027 (2004) 259-62.

[12] R. Levi, S. McNiven, S.A. Piletsky, S.H. Cheong, K. Yano, I. Karube, Optical detection of chloramphenicol using molecularly imprinted polymers, Analytical Chemistry 69 (1997) 2017-2021.

[13] S. Al-Kindy, R. Badia, J-L. Suarez-Rodriguez, M-E. Diaz-Garcia, Room-temperature phosphorescent complexes with macromolecular assemblies and their (bio)chemical applications, Critical Reviews in Analytical Chemistry 30 (2000) 291-309.

[14] M. Zourob, S. Elwary, A. Turner, Principles of Bacterial Detection: Biosensors, Recognition, Receptors and Microsystems", Springer ISBN: 978-0-387-75112-2, 2008

[15] G.H. Cross, A.A. Reeves, S. Brand, M.J. Swann, N.J. Freeman, J.R. Lu, The metrics of surface adsorbed small molecules on the Young's fringe dual-slab waveguide interferometer, Journal of Physics D - Applied Physics, 37 (2004) 74-80

[16] A. Kugimiya, T. Takeuchi, Surface plasmon resonance sensor using molecularly imprinted polymer for detection of sialic acid, Biosensors \& Bioelectronics 16 (2001) 1059-62. 
481

482

483

484

485

486

487

488

489

490

491

492

493

494

495

496

497

498

499

500

501

502

503

504

505

506

507

508

[17] H. Berney, K. Oliver, Dual polarization interferometry size and density characterisation of DNA immobilisation and hybridisation, Biosensors and Bioelectronics 21 (2005) 618-626.

[18] B. Lillis, M. Manning, H. Berney, E. Hurley, A. Mathewson, M.M. Sheehan, Dual polarisation interferometry characterisation of DNA immobilisation and hybridisation detection on a silanised support, Biosensors and Bioelectronics 21 (2006) 1459-1467.

[19] S. Lin, C.K. Lee, Y.H. Lin, S.Y. Lee, B.C. Sheu, J.C. Tsai, S.M. Hsu, Homopolyvalent antibodyantigen interaction kinetic studies with use of a dual-polarization interferometric biosensor, Biosensors and Bioelectronics 22 (2006) 715-721.

[20] S. Ricard-Blum, L.L. Peel, F. Ruggiero, N.J. Freeman, Dual polarization interferometry characterization of carbohydrate-protein interactions, Analytical Biochemistry 352 (2006) 252-259.

[21] M.J. Swann, L.L. Peel, S. Carrington, N.J. Freeman, Dual-polarization interferometry: an analytical technique to measure changes in protein structure in real time, to determine the stoichiometry of binding events, and to differentiate between specific and nonspecific interactions, Analytical Biochemistry 329 (2004) 190-198.

[22] J.R. Lu, M.J. Swann, L.L. Peel, N.J. Freeman, Lysozyme adsorption studies at the silica/water interface using dual polarization interferometry, Langmuir 20 (2004) 1827-1832.

[23] E.A. Yates, C.J. Terry, C. Rees, T.R. Rudd, L. Duchesne, M.A. Skimore, R. Lévy, N.T.K. Thanh, R.J. Nichols, D.T. Clarke, D.G. Fernig, Protein-GAG interactions: new surface-based techniques, spectroscopies and nanotechnology probes, Biochemical Society Transactions 34 (2006) 427-443.

[24] Y. Tang, J.R. Lu, A.L. Lewis, T.A. Vick, P.W. Stratford, Structural effects on swelling of thin phosphorylcholine polymer films, Macromolecules 35 (2002) 3955-3964.

[25] M.S. Lord, M.H. Stenzel, A. Simmons, B.K. Milthorpe, Lysozyme interaction with poly(HEMA)based hydrogel, Biomaterials 27 (2006) 1341-1345.

[26] C. Aulin, I. Varga, P.M. Claesson, L. Wågberg, T. Lindström, Buildup of polyelectrolyte multilayers of polyethyleneimine and microfibrillated cellulose studied by in situ dual-polarization interferometry and quartz crystal microbalance with dissipation, Langmuir 24 (2008) 2509-2518.

[27] S.M. Reddy, G. Sette, G. Q. Phan, Electrochemical probing of selective haemoglobin binding in hydrogel-based molecularly imprinted polymers, Electrochimica Acta 56 (2011) 9203-9208. 
509 [28] V.A. Briand, V. Thilakarathne, R.M. Kasi, C.V. Kumar, Novel surface plasmon resonance sensor

510 for the detection of heme at biological levels via highly selective recognition by apo-hemoglobin,

511 Talanta $99(2012)$ 113-118.

512 [29] H. Pandha, K.D. Sorensen, T.F. Orntoft, S. Langley, S. Hoyer, M. Borre and R. Morgan, Urinary

513 engrailed-2 (EN2) levels predict tumour volume in men undergoing radical prostatectomy for

514 prostate cancer, BJU International 110(6) E287-E292. 
Captions for Figures/Tables:

516

517

518

519

520

521

522

$523 \quad$ Figure 3

524

525

526

527

528

529

530

531

532

533

534

535

536

537

538

539

540

541

542

543

544

Figure 1

Table 2
Figure 2

Changes in thickness (-x-), mass (-o-) and layer density ( -$)$ following the deposition of $\mathrm{BHb}$ upon the sensor surface.

Changes in thickness (-x-), mass (-o-) and layer density ( - ) of deposited protein layer as a result of the injection of MIP 2 HydroMIP gel samples.

Table 1 Changes in thickness, mass and density of a pre-deposited BHb layer and following the injection of NIP and MIP1 to MIP3 gel samples.

Thickness, mass, density and refractive index changes after injecting either: whole; 1:10 diluted serum; or 1:100 diluted serum or plasma followed by $100 \mu \mathrm{g} / \mathrm{ml}$ BSA over BSA MIPs.

\section{Author Biographies:}

Dr Reddy gained a $1^{\text {st }}$ Class BSc in Chemistry (1990) and PhD in Membrane-based electrochemical biosensors (1991-1994) from the University of Manchester. He conducted post-doctoral research at the University of Wales, Bangor (1994-1997) and UMIST (19971998), followed by securing an academic position at the University of Surrey (1998-present). He is currently a Senior Lecturer in Applied Analytical Chemistry at the University of Surrey and has had a long interest in developing molecularly selective smart materials for small molecule speciation in the development of electrochemical biosensors. More recently, he has specialised in large biomolecule recognition and developed synthetic antibody technologies using hydrogel-based molecular imprinted polymers (HydroMIPs). He has published over 40 papers and book chapters.

Dr Hawkins obtained his BSc in Biomedical Sciences from the University of West England. He is a Ph.D graduate from the University of Surrey (where he developed protein MIPs) and has recently qualified as a medical practitioner. 
Dr Phan obtained his BEng in Electronics and PhD in protein imprinted polymers from the

546 Department of Chemistry at the University of Surrey. His research interests were in 547 developing smart materials for biorecognition and biosensors.

548 Dr. Stevenson is a Senior Lecturer in Analytical Chemistry. His main interests are in analytical 549 toxicology, particularly biomedical and environmental analysis. He is a chemistry graduate 550 with a PhD in Analytical Biochemistry. Much of his work has involved the use of 551 chromatography (HPLC, GC, SPE) and immunoassay to measure trace organics such as drugs, 552 pesticides and other trace organics in complex samples. As well as developing novel 553 selective sample preparation techniques, he has also used antibodies and MIPs to develop 554 simplified analytical methods. He is a member of Council of the Royal Society of Chemistry 555 and was previously vice-President of the Analytical Division. He was also President of the 556 Chromatographic Society. In 2007, he was presented with the Analytical Separations Medal 557 of the Royal Society of Chemistry.

558 Dr Warriner gained a 1st Class BSc (Hons) in Food Science specializing in food microbiology from 559 Nottingham University, UK and PhD in Microbial Physiology at the University of Wales Aberystwyth. 560 In 1994 he joined the University of Manchester and developed reagentless sensors designed for 561 routine monitoring on analytes outside of the laboratory environment. Keith subsequently joined 562 the Division of Food Sciences at Nottingham University in 1997. Here work included the 563 development and validation of UV-lasers for package sterilization, DNA-fingerprinting to identify of 564 cross-contamination points in pork processing and the interaction of human pathogens with growing 565 salad vegetables/sprouted seeds. He joined the Department of Food Science within the University of 566 Guelph in 2002 as an Assistant Professor in food microbiology. Current projects include studying the 567 interaction of human pathogens with growing plants, novel decontamination methods in the fresh 568 produce industry, molecular epidemiology of enteric contamination within meat chains and 569 development of reagentless biosensors for biohazard detection. 
Table 1 The quantified changes in thickness, mass and density of a pre-deposited $\mathrm{BHb}$ layer and following the injection of NIP and MIP 1 to MIP 3 gel samples.

\begin{tabular}{c|c|c|c|}
\hline Name & Th / nm & $\begin{array}{c}\text { Mass } \\
\left(\mathbf{n g} / \mathbf{m m}^{2}\right)\end{array}$ & $\begin{array}{c}\text { Density } \\
\left(\mathbf{g} / \mathbf{c m}^{\mathbf{3}}\right) \\
(\mathbf{\pm 0 . 0 2} \\
\left.\mathbf{g} / \mathbf{c m}^{\mathbf{3}}\right)\end{array}$ \\
\hline BHb & 2.74 & 1.99 & 0.73 \\
\hline NIP Injection 1 & 2.67 & 1.96 & 0.73 \\
\hline NIP Injection 2 & 2.87 & 2.05 & 0.72 \\
\hline & & & \\
\hline BHb & 4.32 & 2.39 & 0.55 \\
\hline MIP 1 Injection 1 & 4.42 & 2.46 & 0.56 \\
\hline MIP 1 Injection 2 & 3.91 & 2.22 & 0.57 \\
\hline & & & \\
\hline BHb & 4.43 & 2.48 & 0.56 \\
\hline MIP 2 Injection 1 & 3.38 & 2.31 & 0.68 \\
\hline MIP 2 Injection 2 & 3.26 & 2.26 & 0.70 \\
\hline BHb & & & \\
\hline MIP 3 Injection 1 & 3.47 & 2.04 & 0.53 \\
\hline MIP 3 Injection 2 & 3.26 & 1.88 & 0.55 \\
\hline & & & 0.56 \\
\hline & & & \\
\hline
\end{tabular}




$\begin{array}{lllll}\text { Sample } & \text { Thickness } & \text { Mass } & \text { Density } & \text { Refractive } \\ \text { dilution } & \mathrm{nm} & \mathrm{ng} / \mathrm{mm}^{2} & \mathrm{~g} / \mathrm{cm}^{3} & \text { index }\end{array}$

BSA MIP

Plasma reloading

$\begin{array}{cc}0 & 1.28 \\ 1 \text { in } 10 & 0.95 \\ 1 \text { in } 100 & 0.52\end{array}$

0.75

0.58

1.44

.95

0.53

0.56

1.44

0.20

0.38

1.41

After $100 \mu \mathrm{g} / \mathrm{ml}$ BSA reloading

$\begin{array}{cl}0 & 1.13 \\ 1 \text { in } 10 & 0.94 \\ \text { in } 100 & 0.39\end{array}$

0.68

0.60

1.44

0.94

0.51

0.54

1.43

0.12

0.31

1.39

BSA MIP

Serum reloading

$\begin{array}{cc}0 & 0.97 \\ 1 \text { in } 10 & 2.85 \\ 1 \text { in } 100 & 0.15\end{array}$

0.68

0.70

1.46

0.80

0.28

1.39

0.09

0.57

1.44

After $100 \mu \mathrm{g} / \mathrm{ml}$ BSA reloading

$\begin{array}{cc}0 & 0.76 \\ 1 \text { in } 10 & 2.02 \\ 1 \text { in } 100 & 1.45\end{array}$

0.60

0.78

1.48

0.63

0.31

1.39

0.66

0.45

1.42

Table 2 Thickness, mass, density and refractive index changes after injecting either: whole; 1:10 diluted serum; or 1:100 diluted serum or plasma followed by $100 \mu \mathrm{g} / \mathrm{ml}$ BSA over BSA MIPs. 


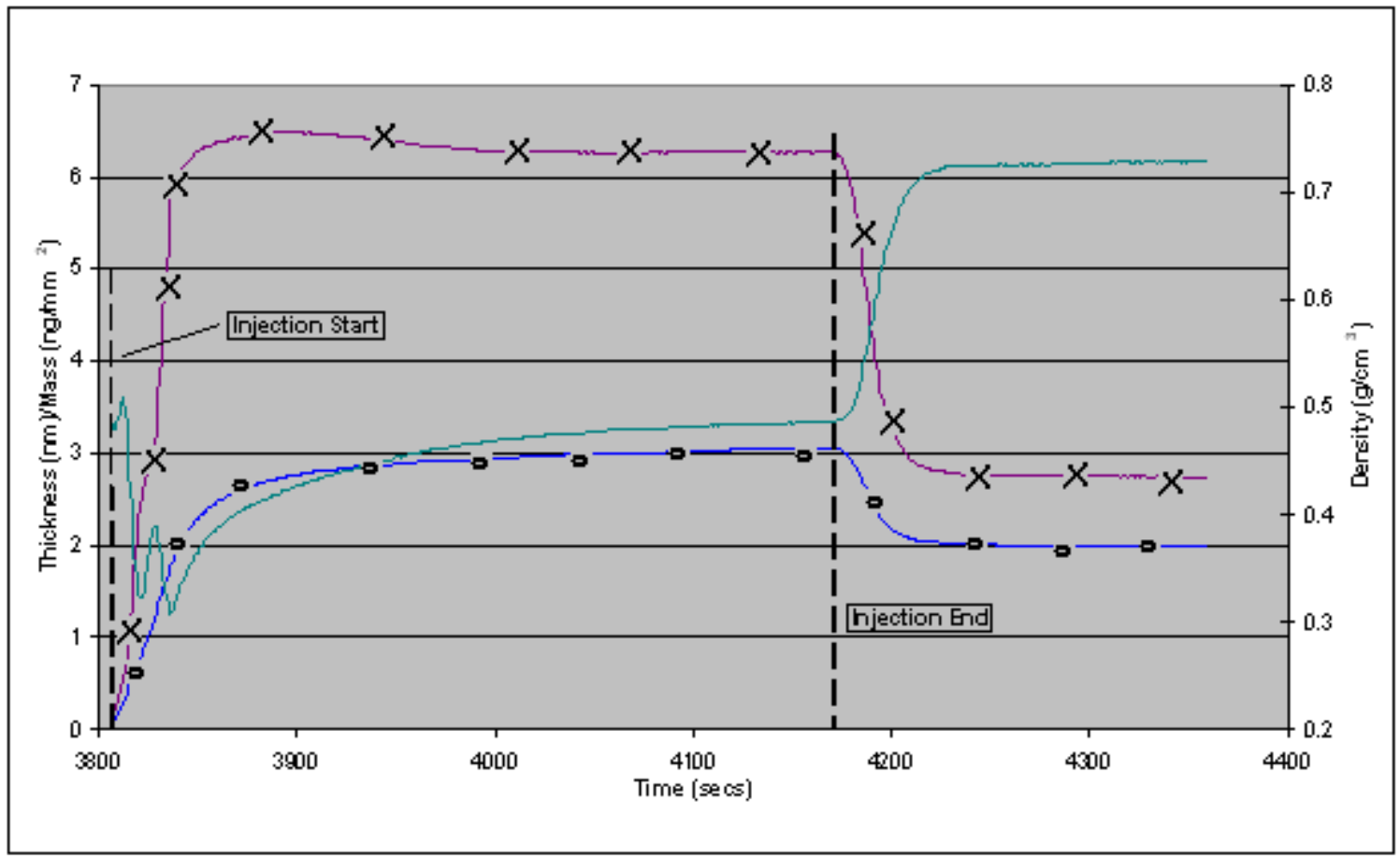

Figure 1 Changes in thickness $(-x-)$, mass $(-0-)$ and layer density $(-)$ following the deposition of $\mathrm{BHb}$ upon the sensor surface. 


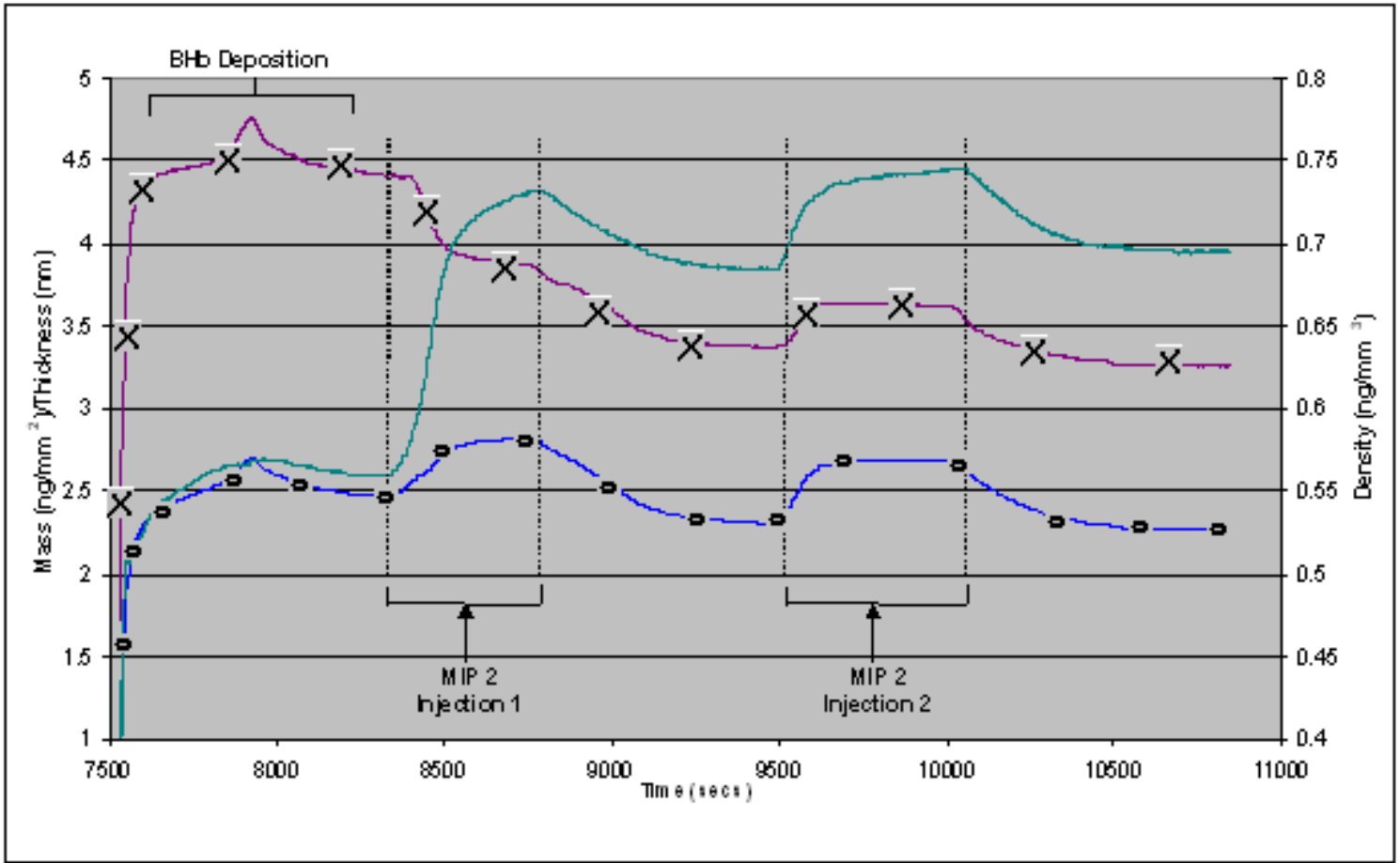

Figure 2 Changes in thickness (-x-), mass (-o-) and layer density ( - ) of deposited protein layer as a result of the injection of MIP 2 HydroMIP gel samples. 


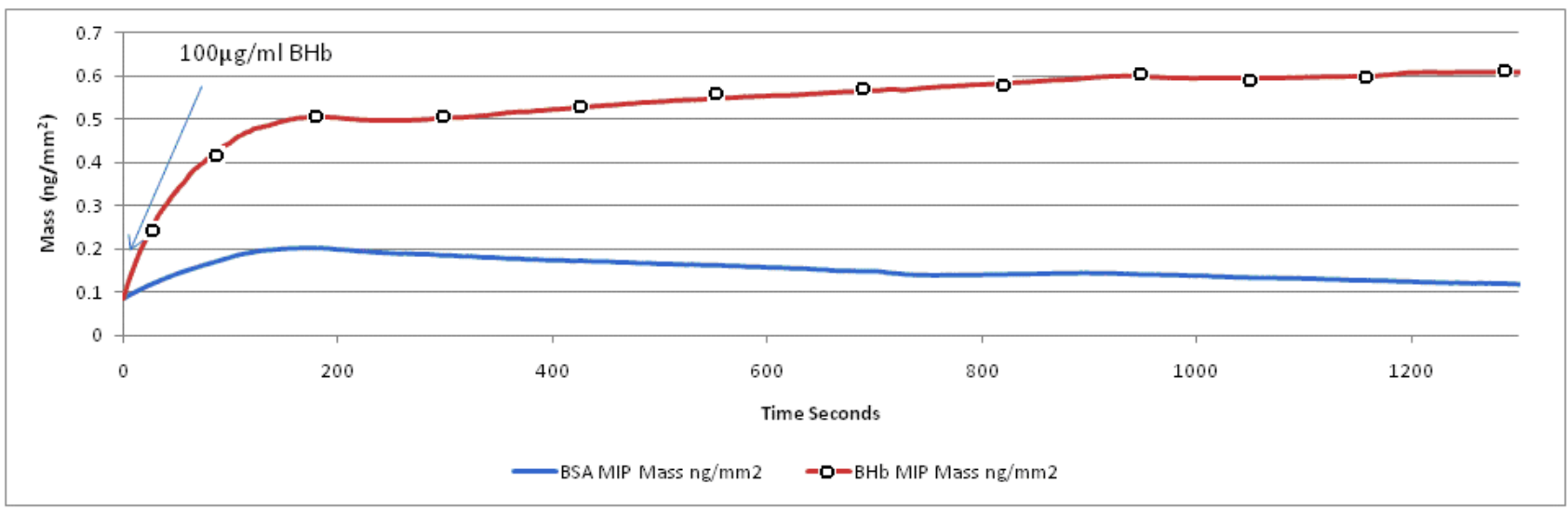

Figure 3: DPI mass response for BSA MIP (bottom trace), and BHb MIP (top trace) when reloading $100 \mu \mathrm{g} / \mathrm{ml} \mathrm{BHb}$. 